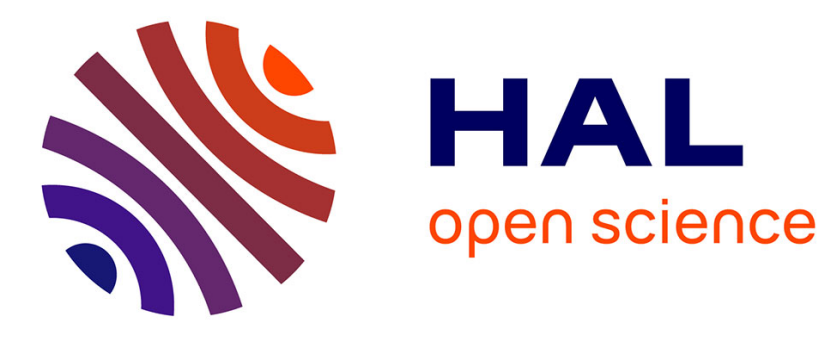

\title{
The West Digital Conservatory of Archaelogical Heritage Project
}

Jean-Baptiste Barreau, Ronan Gaugne, Yann Bernard, Gaétan Le Cloirec, Valérie Gouranton

\section{- To cite this version:}

Jean-Baptiste Barreau, Ronan Gaugne, Yann Bernard, Gaétan Le Cloirec, Valérie Gouranton. The West Digital Conservatory of Archaelogical Heritage Project. DH, 2013, France. pp.1-8. hal00881775

\section{HAL Id: hal-00881775 \\ https://hal.science/hal-00881775}

Submitted on 8 Nov 2013

HAL is a multi-disciplinary open access archive for the deposit and dissemination of scientific research documents, whether they are published or not. The documents may come from teaching and research institutions in France or abroad, or from public or private research centers.
L'archive ouverte pluridisciplinaire HAL, est destinée au dépôt et à la diffusion de documents scientifiques de niveau recherche, publiés ou non, émanant des établissements d'enseignement et de recherche français ou étrangers, des laboratoires publics ou privés. 


\section{The West Digital Conservatory of Archaeological Heritage project}

\author{
Jean-Baptiste Barreau \\ CNRS - CReAAH \\ Rennes, France \\ Yann Bernard \\ Univ. of Rennes 1 - CReAAH \\ Rennes, France
}

\author{
Ronan Gaugne \\ Univ. of Rennes 1 - IRISA \\ Rennes, France \\ Gaétan Le Cloirec \\ Inrap - CReAAH \\ Rennes, France
}

\author{
Valérie Gouranton \\ Insa de Rennes - IRISA \\ Rennes, France
}

\begin{abstract}
The West Digital Conservatory of Archaeological Heritage project, a.k.a. WDCAH, is a new French research organization whose aim is to both ensure the preservation of digital archaeological data, and deliver expertise in production, analysis, visualization and virtual reality exploration techniques. This project is an interdisciplinary project composed of engineers and researchers in archaeology, computer science, virtual reality and 3D interaction with virtual environments. The major objectives of this conservatory project are: (i) sustainable and centralized safeguarding and archiving of $2 \mathrm{D} / 3 \mathrm{D}$ data produced by the archaeological community; (ii) free access to metadata; (iii) secure access to data for the different actors involved in scientific projects and (iv) the support and advice for these actors in the 3D data production and exploration through the latest digital technologies, modeling tools and virtual reality systems. This paper focuses on the first activities of the WDCAH which mainly concern digital models production using photogrammetry, 3D laser scans, and 3D computer graphics software. We are currently working on the reconstitution of six archaeological sites located in the west of France ranging from prehistory to the Middle Ages: the Cairn of Carn Island, the covered pathway of Roh Coh Coet, the Goh Min Ru megalithic site, the gallo-roman mansion of Vanesia, the keep of the Château de Sainte-Suzanne, the Porte des Champs of the Château d'Angers. Other proposals are currently under study.
\end{abstract}

Index Terms-Archaeological heritage - digital preservation Virtual archaeology- 3D models.

\section{INTRODUCTION}

As in any scientific discipline, the current production of digital data in the field of archeology follows an exponential growth. And similarly to each of these disciplines, the types and volume of data are fairly different and their evolution is difficult to predict. Without performing a detailed analysis of the needs of archaeologists or attempting a risky definition of

This work is partially funded by the Université Européenne de Bretagne http://www.ueb.eu their field of activity, we assume that these data constitute a true "mass", likely to involve any material remains, dating from prehistoric to contemporary periods, and located anywhere in the world. These multimedia data, multi-thematic and multi-sources are now stored in a fairly isolated way by scattered project or researcher supports, thereby inherently restricted in terms of security, sustainability and sharing possibilities.

Meanwhile, the emergence of data centers enables the storage, searching, sharing, analysis and visualization of very large amounts of data from the private sector but also in scientific research. The concept of associating this kind of tool in the field of archeology is not unprecedented, but it seems appropriate to create a unifying structure to effectively address these issues related to digital archaeologists of the Great West and elsewhere.

The creation of textual or 2D numeric data through technical instruments or surveys in excavation sites is an activity mastered by all researchers in archeology, together with the involved technicians and engineers. 3D scanning of sites also becomes affordable, both technologically and financially, by using photogrammetry that allows a faithful enough 3D capturing of reality. For greater accuracy, 3D scanners can provide highly accurate point clouds but the cost of equipments and the skills necessary for handling these point clouds are often an obstacle to their use.

If these 3D models of archaeological sites help understanding their functions, they also trigger the creation of real assumptions for reconstructions at different periods. The needs of the archaeological community regarding these reconstitutions of structures or environments are indeed 
considerable, because beyond the obvious benefits in terms of valuation of the assets, archaeologists can better understand their functions and collectivities that occupied them. These reconstructions are currently carried out by researchers with personal knowledge of 3D modeling techniques using everchanging tools; or by expensive provides of $3 \mathrm{D}$ contents without effective or efficient sharing of modeling skills.

\section{MISSIONS OF THE PROJECT}

The conservatory project has four major missions, which are in accordance with the London Charter [1]

1. Backup and archive $2 \mathrm{D}$ and $3 \mathrm{D}$ data produced by the archaeological community in a sustainable and centralized depository.

2. Provide free access to metadata, according to [2]

3. Secure data for the different actors involved in scientific projects concerning the development of heritage access.

4. Support and advise the actors in the production processes and archaeological exploration of 3D data through the latest digital technologies, modeling tools and virtual reality systems.

The West Digital Conservatory of Archaeological Heritage 1 aims at being a convenience tool, easy to reach and free for archaeologists in the West of France. It provides a technical and technological accompanying framework in 3D data production, digital storage, and data and metadata access. Various access modes to data and metadata, associated to a set of tools based on virtual reality are provided to support archaeologists in their scientific work. Coherency in the scientific process remains directly handled by archaeologists.

In the production process, 3D models are built in an iterative process centered on the archaeologists' scientific methodology, with a strong emphasis on fidelity with the current hypotheses. Although the current contacts are archaeologists specialized in different disciplines, the project is absolutely open to all experts who can provide some answers to get a most scientifically relevant reconstitution

Overall we target a light easy-to-access framework, with operational tools for users, focused on the support of the archeologists' scientific work.

\section{RELATED WORK}

Digital data for cultural and archaeological heritage represents a very active field of discussion, with a wide variety of concerns, ranging from data production to data access, and encompassing data storage, security, purpose, etc.

$3 \mathrm{D}$ data production techniques can be based on photogrammetry or lasergrammetry [3] when existing material is still available, or completely based on $3 \mathrm{D}$ modeling tools for destroyed or damaged sites, or even a mix of these techniques.

A workflow of tools and procedures must be associated to the $3 \mathrm{D}$ modeling production process, in order to preserve scientific coherency and ensure technical soundness. Koller, Frischer and Humphreys [4] present a set of research

${ }^{1}$ https://cnpao.univ-rennes1.fr/ challenges related to such a workflow, comprising digital rights management for 3D models, metadata for 3D cultural heritage data, uncertainty representation, indexing and search tools for 3D archives, long-term preservation, etc. We believe that these concerns are central for digital archives, and the WDCAH aims at proposing secure controlled access for archaeologists to their own data, together with public access to metadata built around a centralized archiving datacenter platform. The data archiving process is planned to begin in November 2013 with the archiving datacenter platform opening. This one is a common datacenter for all laboratories of the "Observatoire des Sciences de l'Univers de Rennes". It will be managed by a dedicated team with which it was agreed flexibility of use. It will be indeed possible to manage for each project different users and public rights, security, file formats etc. Uncertainty is intrinsic in our iterative process in which $3 \mathrm{D}$ models are produced to allow archaeologists to work on their hypotheses, and propose new ones.

The WDCAH has to be seen as a tool for researchers, in accordance with Pletinckx's position [5]. By pulling together multi-disciplinary actors from archaeology, graphic design, computer science, and virtual reality, such a tool, based on 3D models and data, can be used by archaeologists as a support for reasoning, arguing, visualizing, perceiving, or educating, as illustrated by Le Cloirec [6], and Hermon [16].

In order to support archaeologists in their scientific approach, we propose additional tools beyond visualization around 3D models, such as simulation, interaction and immersion. Vergnieux pointed out the interest of simulation based on 3D models [7][15], and Gaugne et al. illustrated the interest of interaction and immersion for archaeologists in 1:1 scale reconstitutions [8].

The European research project 3D-COFORM [10] promotes tools and methods for the use of 3D models in archaeology and cultural heritage. It proposes to address a large spectrum of the process, from 3D scanning in association with VCC-3D, to dissemination. The project TGE Adonis [11] has a similar offer, but without any production activity: it proposes infrastructures and tools for storage and archiving, but leaves all the data production activity to archaeologists. Archeovision proposes a complete assistance process for large archaeological projects using 3D technologies [9]. The WDCAH aims at acting with local archaeologists at the closest level, being an intermediate step in the access to larger infrastructures.

\section{GLOBAL PROCESS}

In order to ease the access to the WDCAH for archaeologists, we have defined a process focused on scientific efficiency, presented in Fig. 1. First, one or several archaeologists send plans, photos, point clouds or primary $3 \mathrm{D}$ sketches to the conservatory with a form presenting the site metadata (geolocalization, time periods etc.), the nature of the desired models, purpose of the project, archaeological interests and potential interests in terms of heritage valuation. These files are then uploaded on a data server of a shared hosting platform for research computing resources. Using some of 
these data, a specialized team of the WDCAH accompanies the $3 \mathrm{D}$ modeling process using latest scanning and modeling techniques. Where possible, scanned parts may serve as a basis for drawing or be integrated into the $3 \mathrm{D}$ reconstruction. For example, one or several items may remain on the site and their recreation is relevant and likely to be made by photogrammetry or laser scanning. Then follows an iterative exchange between the graphic designers and the archaeologists to produce scientifically relevant 3D models. When the archaeologists are satisfied with the 3D models, they are copied to an archiving server in a shared hosting platform, with all the associated sets of data files. The last step is the diffusion of the data which becomes available for consultation according to permissions through a secure web portal, and also integrated in virtual reality immersive systems such as head-mounted displays or CAVE-like systems to allow archaeologists to work in an immersive mode.

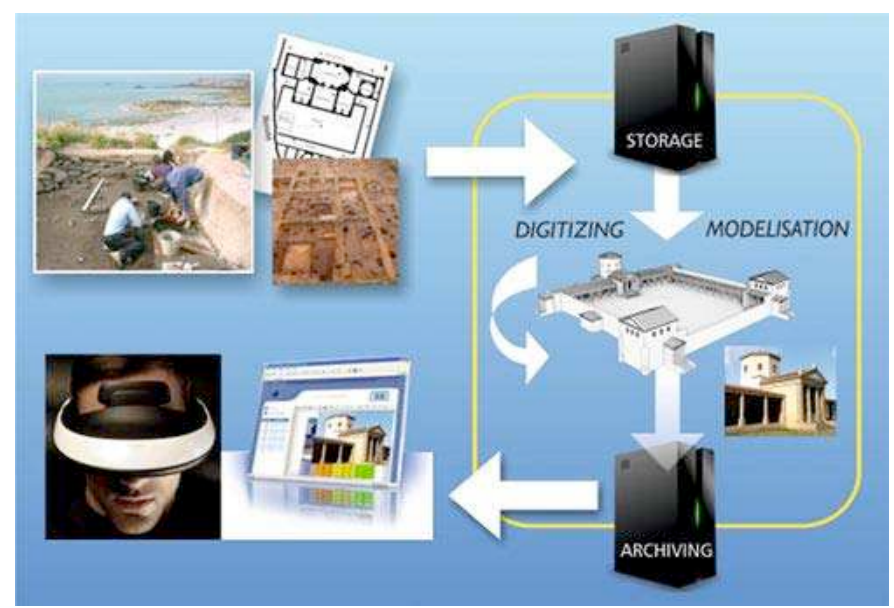

Fig. 1. The WDCAH process

\section{CURRENT PROJECTS}

Among the current projects of the WDCAH, we present two reconstitution projects: the Roh-Coh-Coët monument and the Porte des Champs of the Château d'Angers.

Separated by thousands of years, these two sites have indeed dissimilar sizes, building techniques, functions and levels of complexity.

Each project had well defined scientific goals: a reconstitution of the building process for the first, and a reconstitution at a given period for the second. Input data was composed of a large number of photos in the first case, targeting a photogrammetry-based modeling, and in the second case, of floor plans and cross sections used as a basis for manual $3 \mathrm{D}$ modeling with several photos for texturing.

\section{A. Roh Coh Coet}

In the heart of the Landes de Lanvaux granite massif, the Roh-Coh-Coët monument (see Fig. 2.) lies in Saint-JeanBrévelay, in the west of the Britton village called Kerherne Budunan. The builders of this monument had the ingenious idea of building a rock burial place within a natural outcrop.
Because the length of this outcrop is eight meters, it was enough to juxtapose supports and cover everything with stone slabs. Oriented east-west with the entrance facing east, this covered pathway overlooks a beautiful valley, merges and blends with its natural surroundings. The total length is $8.0 \mathrm{~m}$ with an average width of $1.60 \mathrm{~m}$ and an approximate height of $1.20 \mathrm{~m}$.

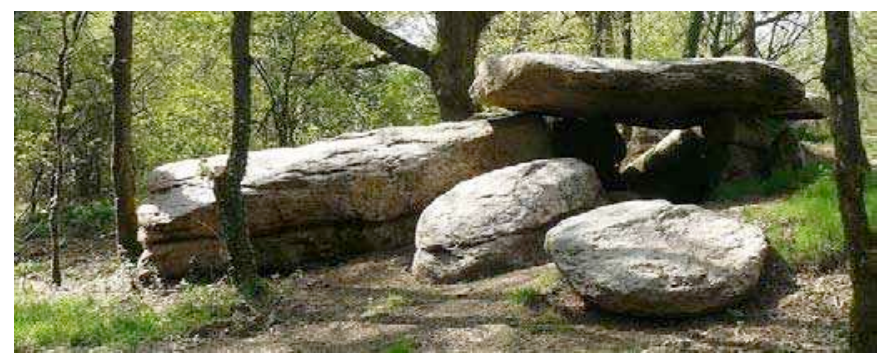

Fig. 2. The Roh Coh Coet monument

The reconstituted phasing highlights the steps that were used to build a megalithic monument as a covered pathway based on elements naturally provided by the rock outcrop. An internal cross slab appears to have been used for internal compartmentalization. A small wall of dry stones, a few planted slabs and two cover slabs constitute the rest of the monument. The whole monument blends so seamlessly with its natural environment that it is impossible to discern when looking at it from the west. This fine example of architectonic ingenuity also highlights the symbiosis between natural and anthropogenic elements.

The goal of using 3D for the study of this site is to address two issues that are unfeasible in reality without destroying the site: validating the architectural construction phases and testing the coincidence between the two main bearing rocks.

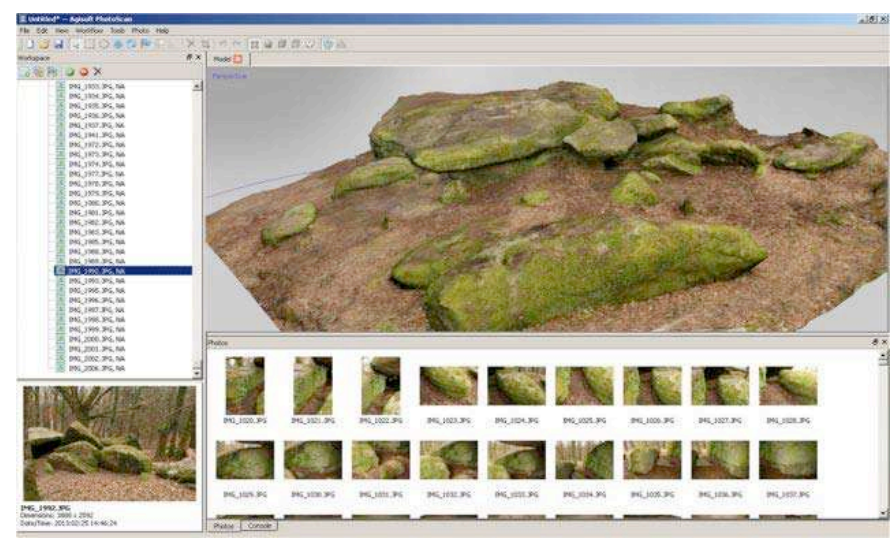

Fig. 3. Photoscan photogrammetry

Regarding the phasing, there first was a need to model the volume of the rocks. From 880 photos taken by the archaeologist, we generated a point cloud and a mesh presented in Fig. 3. using the PhotoScan photogrammetry software [12] in a few hours. A $3 \mathrm{D}$ graphic designer from the WDCAH then imported, reworked and smoothed the mesh in 3DSMax [13], as presented in Fig. 4. 


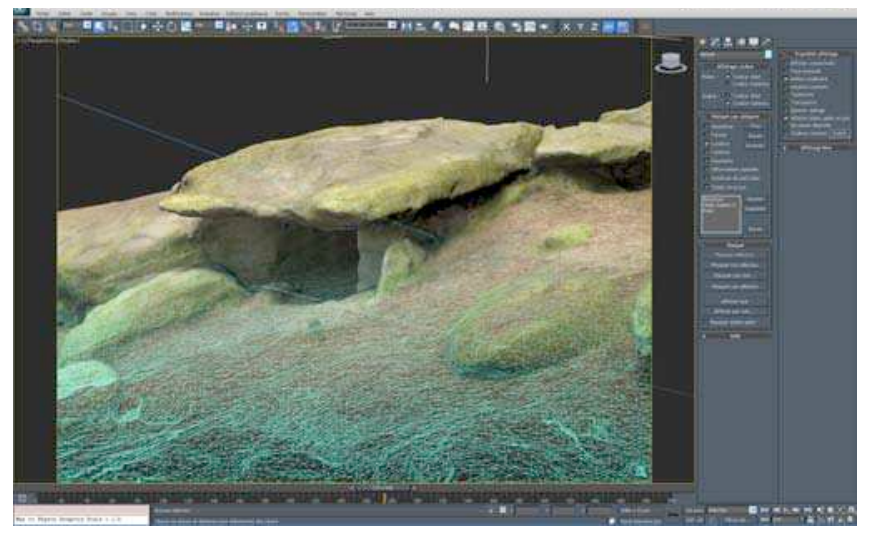

Fig. 4. Work on the mesh in 3DS Max

From this volume, the graphic designer isolated and modeled the main components of the structure by drawing hidden parts that were related to "gray areas". Once the volumes were built, the archaeologist submitted a 2D phasing diagram (see Fig. 5) to the 3D artist who, after a few discussions, produced 3D animations formulating building hypotheses, see Fig. 6. In this way, the identification and positioning of the blocks closing the structure, which were indecipherable in the initial mesh, became clear. Operations such as the addition of a rotation for a support block, or the linking between a small slab initially isolated and the monument have been identified and validated. This led to relevant ways for understanding the building process of the rock burial pathway from natural elements.
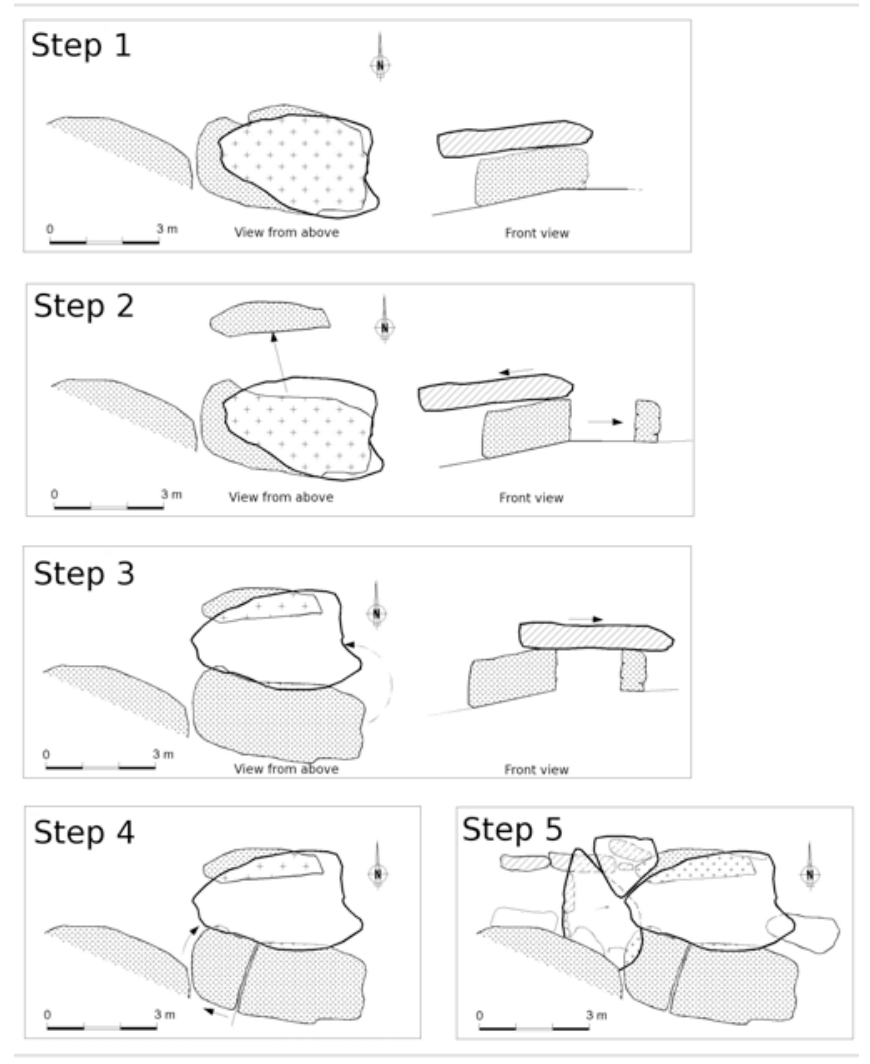

Fig. 5. 2D diagram of the phasing

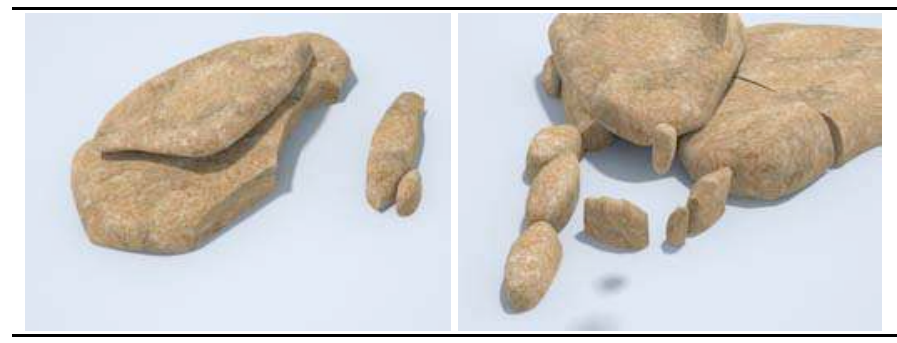

Fig. 6. 3D animation of the building steps

Then the archaeologist needed to verify quantitatively that the two main structural slabs came from the same rock that had been cut up by the builders. In order to achieve this, we first imported the point cloud from the photogrammetry software in the 3D point cloud opensource software Cloudcompare [14], we cleaned up the 3D scene and isolated the opposite surfaces of the two slabs with a segmentation tool. Then we made a first manual alignment before using the automatic entities alignment tool. Figure Fig. 7. indicates the resulting areas of greater or lesser proximity between the surfaces, delivering archaeologists with a solid basis of discussion about the hypotheses and conditions of cutting an initial slab.
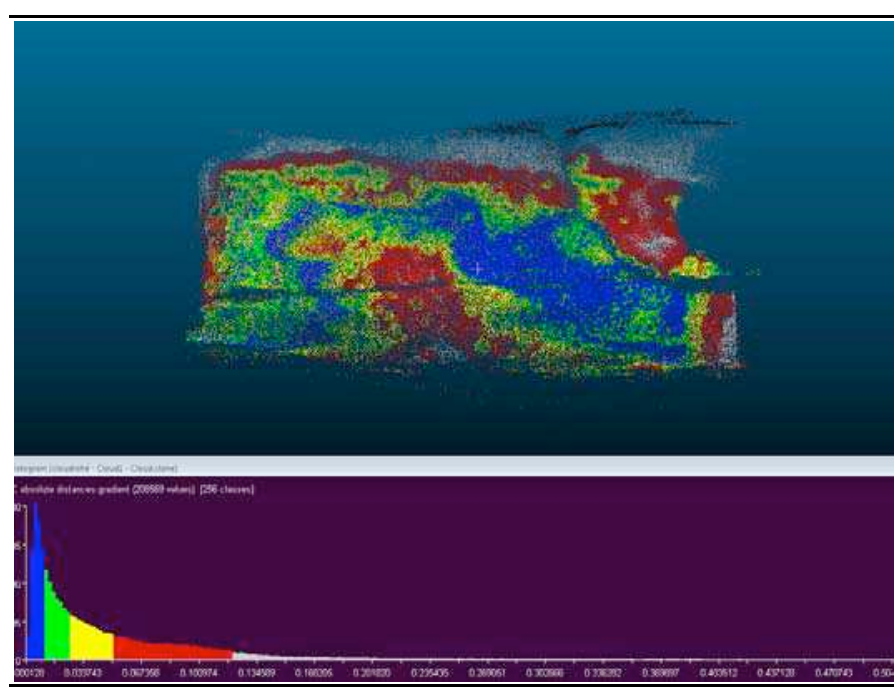

Fig. 7. Coincidence study

\section{B. "Porte des Champs" of the "Château d'Angers"}

We now focus on the Porte des Champs of the Chateau $d^{\prime}$ Angers and its immediate environment as it was in the middle of the thirteenth century (1230 - circa 1250). The construction of the Chateau d'Angers started in 1230 by Blanche de Castille and St. Louis. It is located in the heart of the city of Angers and managed by the Service Archéologique Départemental de Maine-et-Loire and the Centre des Monuments Nationaux (CMN). The Porte des Champs is composed of towers $n^{\circ} 9$ and 10 which are located in the southeast (Fig. 8. ) and served as a link between the castle and the city. It is the most attractive architectural element of the castle and one of the most 
important defensive achievements of the thirteenth century in Western Europe. The archaeological site has received an extensive study conducted by the Service Archéologique $d u$ Département du Maine-et-Loire (SADML), which was able to recover historical layout maps. These maps include the Porte des Champs, tower $n^{\circ} 11$, the curtain wall between towers 10 and 11 and various defensive facilities: drawbridge, portcullis, postern, etc. While the Porte des Champs is well preserved, Fig. 9. , its appearance has drastically evolved over time.

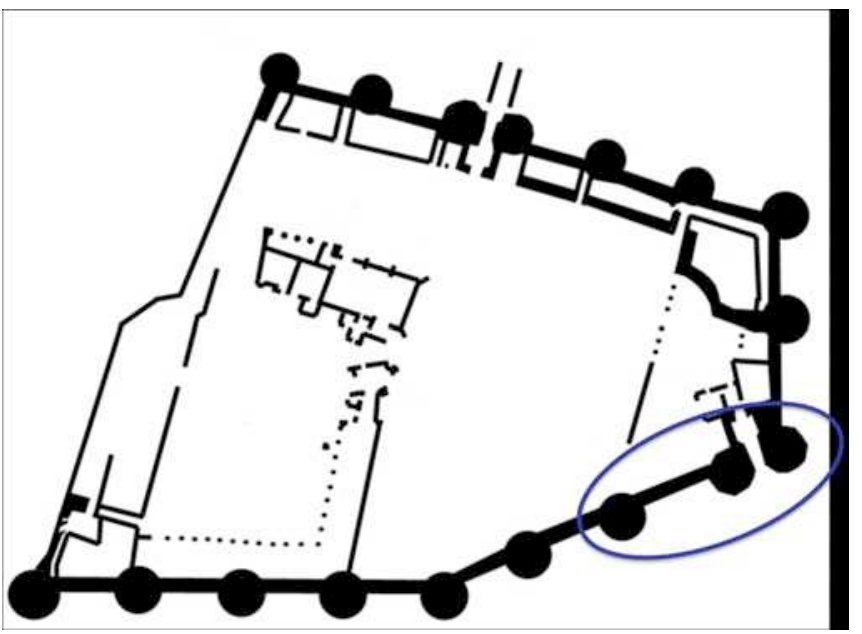

Fig. 8. Localization of the study

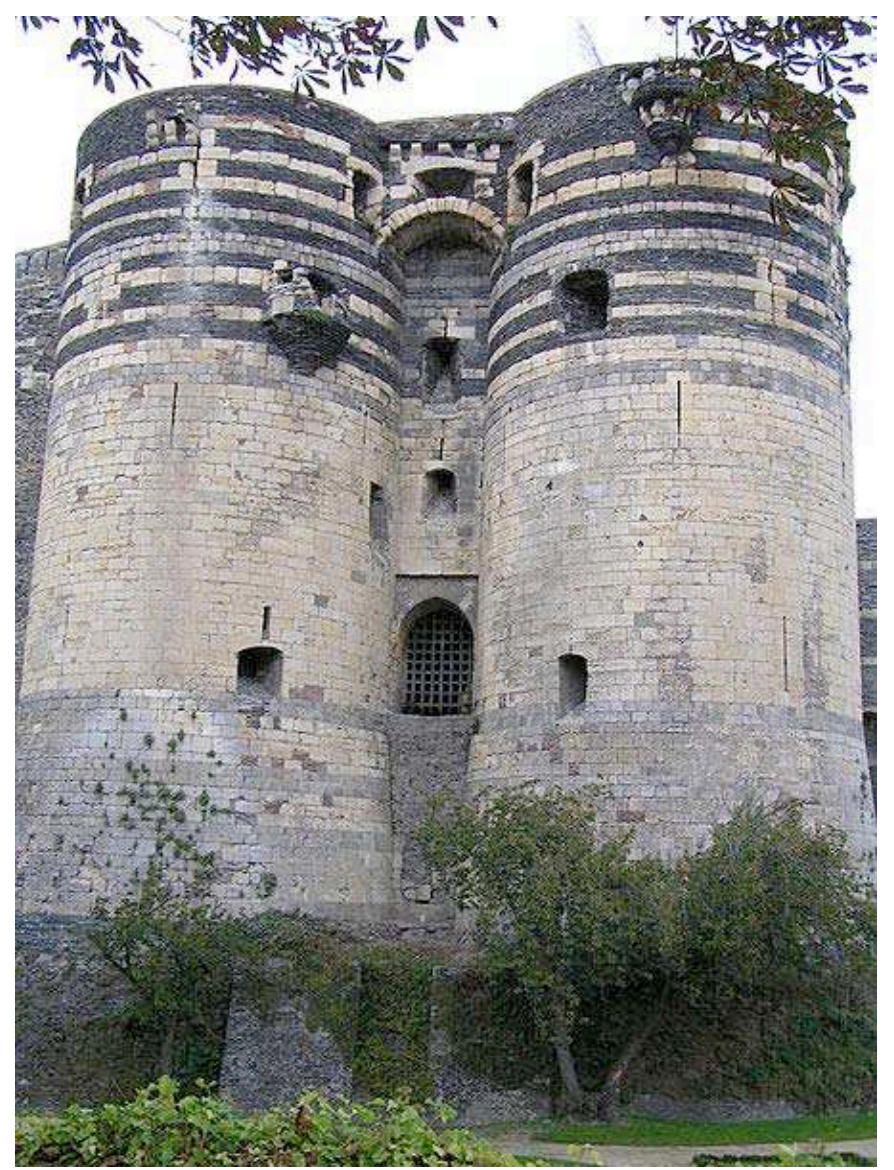

Fig. 9. Current appearance of the « Porte des Champs »
The goal of using 3D for the study of this site is to propose a representation of the door from the outside as it might have been in the thirteenth century. We first used photos and measurements to create a non-textured model representing the current state of the site, Fig. 10. We then remodeled and textured the result to transform it into what it was like in medieval times. In our progress, the images successively produced and modified did establish a communication support to nourish our exchanges with archaeologists.

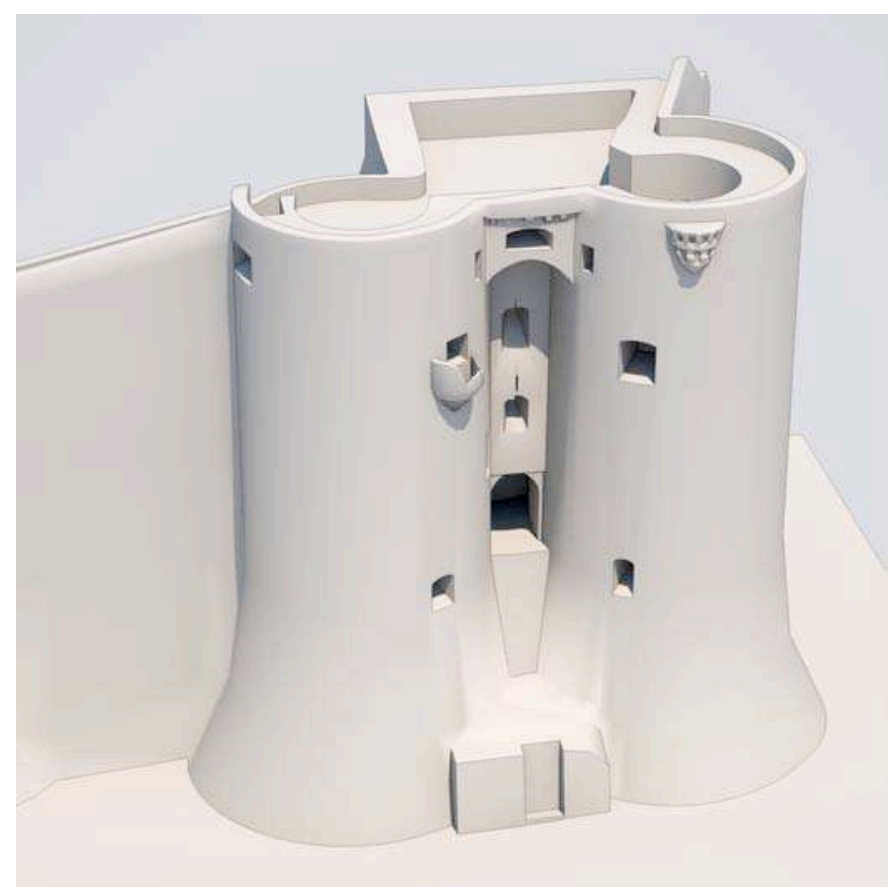

Fig. 10. Initial iteration : current state non-textured modeling

\section{a/ The towers}

Because they were built later, the watchtowers, the gunboats, the rectangular rebate framing the door and the parapet overhanging above were removed from the model. The three towers those were higher than in the current state have been raised. Based on some photos provided by archaeologists, the graphic designer textured the equipment of the towers composed of shale, limestone and sandstone. More specifically, he applied a rock texture with an irregularly embossed design to the lower half of the towers slope and to the curtain wall, and a gray-beige sandstone to towers $n^{\circ} 9-10$. The three limestone chainings at the top of the towers have also been expanded.

\section{b/ The arrow slits}

The arrow slits were textured to be a few centimeters wide, and positioned thanks to pictures and discussions. We chose to represent these elements directly on the texture rather than modeling them in the mesh for convenience, since we only focus on an external representation at this step of the project. 
Texturing work around arrow slits has been strengthened by adding frames, lintels and limestone foundations.

\section{c/ The hoardings}

Hoardings, which are irregular constructions made of planks and covered with slates, were present on the curtain wall and towers. Those of the Château d'Angers have completely disappeared, so we based our reconstitution on those still in place and from the same time, of the Château de Laval. After an initial proposal, we were advised to add external columns to hold the planks, to modify the overhang, the block size of the curtain wall, the number and variety of openings and to leave some holes in the floor to allow projectiles dropping.

\section{d/ The roofs}

The roof was textured using a photo of an eleventh century slate cover which has been then slightly thickened. For the top of the roofs, the graphic designer has drawn a kind of punch, which is a vertical part shaping the axis of the roof, and adorned with a lead sheet covering the top of the slate cone. For the roof of the guardhouse, it was restored in lead. The chimney stack has been split into two separate conduits.

\section{e/ The gateway}

The gateway was first built using brick piers, then replaced by shale following the archeologist's advice. The upper parts of passages drilled through the piers were rounded arches. For the overpass, a railing made of bollards reinforced by oblique wooden pieces was added.

\section{f/ The moats}

Archaeologists have informed us that the size of moats should match what was found on other sites, i.e. $15 \mathrm{~m}$ wide and $8 \mathrm{~m}$ deep. They should not be full of water, although a stream may have been present at the bottom. So we modeled a small stream surrounded by a little vegetation.

\section{$\mathrm{g} /$ The defensive wall}

Since some points of view we chose showed some of the surrounding environment, we included parts of the wall enclosing the city.

The current iteration rendering, presented in Fig. 11. was produced two months and half after the kick-off of the project, after about forty emails and ten confcall meetings.

These first renderings are still a source of interesting discussions for archaeologists and, following our philosophy to stay available for any modification, there are chances that this model will continue evolving to try to reach the most scientifically convincing representation.

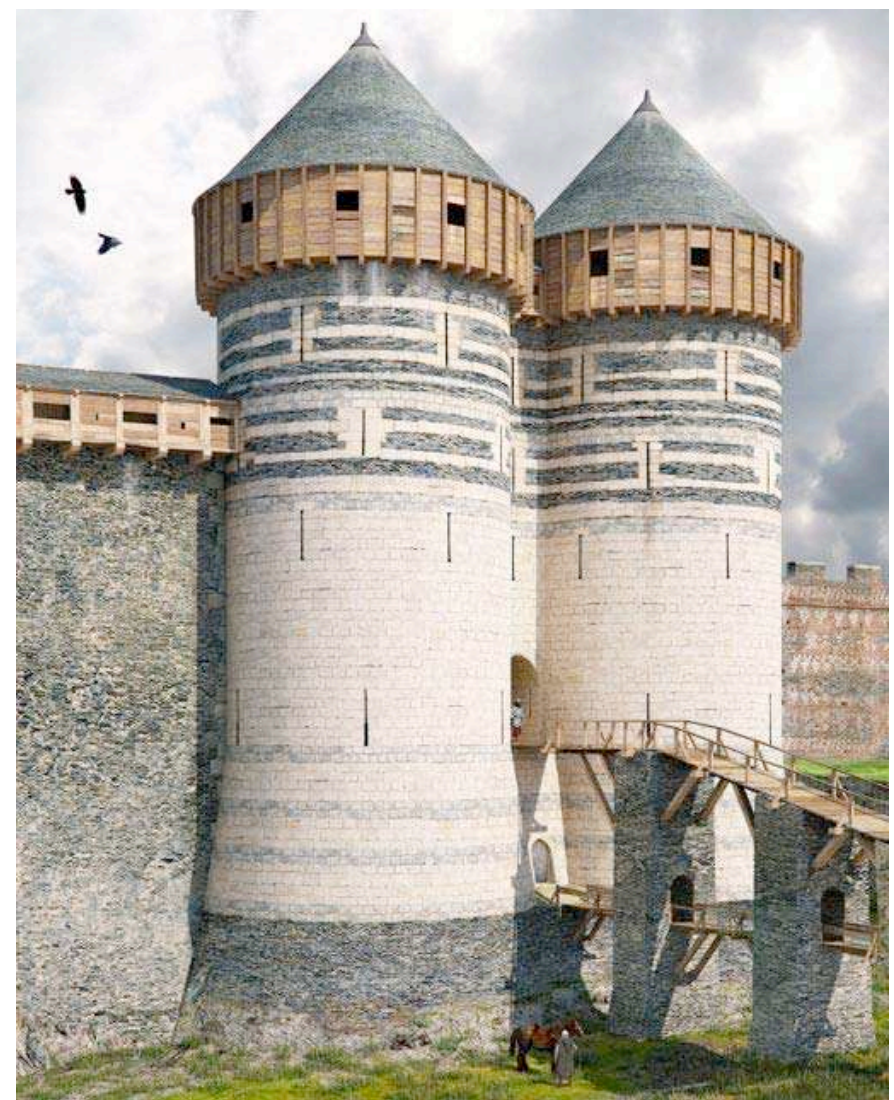

Fig. 11. Current iteration in the $3 \mathrm{D}$ reconstitution

\section{DISCUSSION}

Each time new tools emerge in the archaeological community, scientists are generally divided between curiosity and distrust. The arrival of CAD or the integration of digital photographs in reports had already created heated debates around archives conservation or the ease in which certain terrain observations could be altered or even deleted. Even today, the reluctance around data acquisition and 3D reconstitution stems from a lack of understanding of the technology and its rigor, but also from a lack of faith in the scientific approach of the archaeologists. It is true that both the technology and the scientific approach go hand in hand, but we should also note that the quality of this kind of archaeological work needs a minimal understanding of how the underlying hardware and software behave.

Still today, certain colleagues need demonstrations through concrete examples, to grasp the values of these tools. It is most probably the fear of losing control of a link in the chain of operations of their field that sets them back. Archaeology still hangs onto tradition when, not so long ago, a researcher could go through the entire process alone, from sketching to writing articles while also doing the topography of the site and camp cooking. It is never easy to admit to not being able to run a $3 \mathrm{D}$ scanner or create 3D models and that we have to delegate these tasks. However, it is essential to know how these tools work 
and what they can do so that we can make the correct requests to the right people.

But excess in the opposite direction is also problematic: archaeologists can have very high expectations and are often disappointed by the limits imposed by the technology. This drives the necessity to synchronize technological possibilities with scientific enthusiasm. It is furthermore necessary to keep looking for new and more adequate solutions so as to nourish the research in both fields.

This is where the WDCAH can foster a climate of comprehension between field archaeologists and computer scientists. This conservatory is designed as a meeting place where tools and skills join together to better support archaeological works, increase their value and better preserve and disseminate them. Such a space is definitely federative for researchers with different backgrounds. This article is the written proof of this federation through the gathering of CNRS, IRISA and INRAP. By placing itself in a perspective other regions have long been committed to, western France certainly gives itself the means to boost its archaeological research.

The WDCAH received a favorable and fruitful greeting from the local archaeologist community. Started six months ago, the WDCAH is currently working on six main projects.

We are aware that the main danger with this kind of project is the dazzling side, inherent in the use of $3 \mathrm{D}$ and VR, which can hide its own scientific missions. Thus we strive to communicate, with the archaeological community, about the requirements we imposed to follow our philosophy and restrict ourselves only to these missions, without getting involved in their research ahead of the reconstitutions. We also consider that cultural heritage valuation is currently out of the scope of our project. The needs in this sector are indeed obvious, but we want to stay focused on the scientific needs.

Installed in the premises of an archaeometry laboratory, the WDCAH cohabits with sixty archaeologists of all specialties who can directly follow our daily activities. So far, the first many exchanges seem to raised interest and led to the creation of a lot of data and reconstitution projects.

Although it is still too early to provide any thorough assessment, the first contribution we perceive to the archaeological community, which matches with our objectives, is the initiation of a technological barriers permeabilization allowing an adaptive, sustainable and extensive integration of 3D tools and virtual reality in archaeologists' task.

\section{CONCLUSION}

By creating this type of structure, our goal is to experiment the integration of $3 \mathrm{D}$ reconstruction and virtual reality techniques in collaboration with a community of archaeologists, who might or might not be aware of such technology but who clearly have many needs. Although the
WDCAH is only a few months old, the first feedbacks seem very positive and reconstitution requests come regularly enough to let us believe in the real value of this project. Provided that we find the funds to continue our existence beyond this year, our will is to lead this project as long as possible while maintaining our philosophy to adapt the WDCAH to the various specific needs of archaeologists.

\section{PERSPECTIVES}

In addition to the six current projects, we are working on the organization of twelve other reconstruction projects combining modeling and digitization (photogrammetry and / or laser scanning): the Landévennec Abbey, a Gallic and GalloRoman farm in Trémeur, the romanesque church of the SacréCoeur in Paray-le-Monial, the Portes Mordelaises in Rennes, a ship of the Compagnie des Indes from the eighteenth century, the Mars temple in Corseul, the Opet temple (Karnak), the camp of Beugy, the Coatfrec castle, a section of the Anse du Verger in Cancale, the neolithic site of Lillemer and the Languidou Chapel. Reconstitution projects of underwater and submarines sites are also under discussion with the Département des Recherches Archéologiques Subaquatiques et Sous-Marines (DRASSM).

Integrations of the first low polygon count $3 \mathrm{D}$ models in a virtual reality head-mounted system are currently underway. Indeed several 3D models have been changed to low-poly meshes and are also currently used in the development of an exploration and interaction module through this helmet. Eventually, this module could be used by archaeologists working with WDCAH for all their models.

From an economic point of view, we have the funds to continue our adventure until the end of this year, thanks to the Université Européenne de Bretagne. However, we are at present unable to say whether we will have the necessary funds to continue the project in an untroubled and effective manner at the end of this period.

\section{ACKNOWLEDGMENT}

We would like to especially thank Mrs. Emmanuel Litoux and Philippe Gouezin, archaeologists at the general councils of Maine-et-Loire and Morbihan, which were the basis of this first works. Nothing would have been possible without their documents, knowledge, didactic answers, patience and commitment.

\section{REFERENCES}

[1] London charter www.londoncharter.org

[2] INSPIRE directive http://inspire.jrc.ec.europa.eu/

[3] S. Gonizzi Barsanti, F. Remondino, and D. Visintini, "Photogrammetry and Laser Scanning for archaeological site 3D modeling - Some critical issues", in Proc. of the 2nd Workshop on 'The New Technologies for Aquileia', V. Roberto, L. Fozzati, June 2012 
[4] D. Koller, B. Frischer, and G. Humphreys, "Research challenges for digital archives of 3D cultural heritage models", in ACM Jounal on Computing and Cultural Heritage, Vol. 2 Iss. 3, Dec. 2009

[5] D. Pletinckx, "Virtual Archaeology as an Integrated Preservation Method," in "Arqueologica 2.0, Proceedings of 1st International Meeting on Graphic Archaeol-ogy and Informatics, Cultural Heritage and Innovation," Seville 17-20 June 2009, pp. 51-55, 2009

[6] G. Le Cloirec, "Les atouts de l'imagerie 3D pour l'archéologie de terrain", proc. of Virtual Retrospect, p. 29-36, 2009

[7] R. Vergnieux, "Virtual Archaeological research and 3D models (Restitution, validation and simulation)/L'usage scientifique des modèles 3D en archéologie, de la validation à la simulation" in Archaeology Review, 2011

[8] R. Gaugne, J.-B. Barreau, F. Cousseau, V. Gouranton. "Largescale immersive reconstitution of a Neolithic corbel dome". In Int. Symp. on Virtual Reality, Archaeology and Cultural Heritage, Nov 2012, Brighton, United Kingdom. pp 1-8

[9] B. Dutailly, P. Mora, R. Vergnieux, "Du bon usage de la 3D en archéologie, un point sur la photogrammétrie", archéopages n³4 - juillet 2012, Inrap Eds., pp.86-89.
[10] J. Kaminsky, D. Pitzalis, and F. Niccolucci, "3D-COFORM: Making 3D documentation an everyday choice for the Cultural Heritage sector", in FOCUS K3D Conf. on Semantic 3D Media and Content , 02/2010, Sophia Antipolis - Méditerranée, France, (In Press)

[11] TGE ADONIS http://www.tge-adonis.fr/

[12] Photoscan http://www.agisoft.ru/products/photoscan/

[13] Autodesk 3D Studio MAX http://www.autodesk.com/

[14] CloudCompare http://www.danielgm.net/cc/

[15] R. Vergnieux. "Virtual Reality : a tool for Archaeologists", in R. Vergnieux and C. Delevoie eds.,Virtual retrospect 2003 : proceedings of the conference, Biarritz, France, November 6th7th 2003 (Bordeaux, 2004), pp. 3-16.

[16] S. Hermon, "Scientific Method, Chaîne Opératoire and Visualization - 3D Modelling as a Research Tool in Archaeology", in Beacham, R., Denard, H. (eds.), Paradata and Transparency in Virtual Heritage, 2012, Ashgate, London, pp. $13-22$. 